\title{
PENGARUH KEBERADAAN MINIMARKET TERHADAP TINGKAT PENDAPATAN PEDAGANG PASAR TRADISIONAL DI KECAMATAN TURIKALE KABUPATEN MAROS
}

\author{
Nurul Hikma ${ }^{1 *}$, Sarnawiah ${ }^{2 * *}$ \\ ${ }^{1,2}$ Universitas Muslim Maros \\ *nurulhikma1207@gmail.com \\ **sarnawiah@umma.ac.id
}

\begin{abstract}
ABSTRAK
Penelitian ini bertujuan untuk mengetahui Pengaruh Keberadaan Minimarket Terhadap Tingkat Pendapatan Pedagang Pasar Tradisonal di Kecamatan Turikale Kabupaten Maros. Data yang digunakan dalampenelitian ini adalah data primer berupa data yang didapatkan dari hasil wawancara. Sementara data sekunder berupa jumlah Minimarket di seluruh Kabupaten Maros yang didapatkan dari Kantor Dinas Koperasi, UMKM, dan Perdagangan (KOPUNDAG), dan Jumlah Minimarket yang didirikan tiap tahun mulai dari tahun 2011 sampai 2018 serta buku-buku dan jurnal yang mengenai Pengaruh Keberadaan Minimarket terhadap Tingkat Pendapatan Pedagang pasar Tradisional.

Metode analisis dalam penelitian ini adalah menggunakan regresi linear sederhana, koefisien korelasi, koefisien determinasi, dan uji t (uji parsial) dengan perhitungan melalui SPSS versi 22. Hasil penelitian menunjukkan bahwa keberadaan Minimarket berpengaruh negatif dan signifikan terhadap tingkat pendapatan pedagang Pasar Tradisonal di Kecamatan Turikale Kabupaten Maros.
\end{abstract}

Kata Kunci : Minimarket dan Tingkat Pendapatan Pedagang

\section{PENDAHULUAN}

\section{A. Latar Belakang}

Manusia telah melakukan kegiatan jual beli sejak mengenal peradaban sebagai bentuk dalam memenuhi kebutuhan hidup baik kebutuhan primer maupun kebutuhan sekunder. Keberadaan pasar merupakan salah satu hal yang paling penting karena tempat untuk melakukan kegiatan jual beli. Pasar menjadi indikator paling nyata dalam kegiatan ekonomi masyarakat suatu wilayah seperti yang terjadi di Indonesia. Bangsa Indonesia telah lama mengenal pasar khususnya pasar tradisional. Di Indonesia keberadaan pasar tradisional bukan semata merupakan urusan ekonomi tetapi lebih jauh kepada norma ranah budaya, sekaligus peradaban yang berlangsung sejak lama diberbagai wilayah
Indonesia. Ditengah arus modernitas yang bermunculnya pasar modern membuat keberadaan pasar tradisional sebagai suatu budaya bangsa saat ini mencoba untuk bertahan dan mengembangkan diri agar bisa bersaing di tengah arus tersebut.

Hal ini terjadi setiap wilayah di Indonesia, salah satu nya Sulawesi selatan. Sulawesi Selatan adalah salah satu provinsi di Indonesia dengan ibu kotanya adalah Makassar yang merupakan kota terbesar keempat di Indonesia dan terbesar di Kawasan Timur Indonesia, memiliki luas areal 175,79 km2 dengan penduduk 1.112.688, sehingga kota ini sudah menjadi kota Metropolitan. Kota Makassar berperan sebagai pusat perdagangan dan jasa, pusat kegiatan industri, pusat kegiatan pemerintahan, 


\section{PAY Jurnal Keuangan dan Perbankan. Vol. 2 No. 1, Juni 2020}

jasa angkutan barang dan penumpang baik darat, laut maupun udara dan pusat pelayanan pendidikan dan kesehatan. Kota Makassar menjadi salah satu kota yang sangat penting didalam pembangunan ekonomi di Indonesia. Kota ini terus menunjukkan pertumbuhan yang sangat progresif yaitu Pertumbuhan jumlah penduduk, industri, perdagangan dan kegiatan ekonomi yang terus dikembangkan. Sejalan dengan perkembangan Kota Makassar, kegiatan ekonomi semakin pesat ini ditandai dengan melaksanakan usaha-usaha pembangunan. Pembangunan tersebut dilakukan di berbagai sektor diantaranya yaitu sektor ekonomi, sektor politik, sektor sosial budaya dan lain-lain.

Upaya pembangunan tersebut dilakukan untuk mengembangkan perekonomian di Makassar dalam rangka meningkatkan taraf hidup masyarakat. Salah satu pembangunan yang sedang dijalankan oleh pemerintah saat ini adalah melalui pembangunan ekonomi. Pembangunan ekonomi mengarah pada kebijakan yang diambil pemerintah guna mencapai kesempatan kerja dan pertumbuhan ekonomi yang berkelanjutan. Salah satu bentuk pembangunan pada sektor ekonomi adalah banyaknya di bangun Pasar Modern.

Pasar modern tersebut terbagi menjadi beberapa skala usaha yakni Hypermarket, Supermarket, dan Minimarket. Pertumbuhan pasar modern itu sendiri disebut kawasan yang mencerminkan suatu bentuk aktifitas perdagangan ritel, pusat perbelanjaan serta daerah hiburan yang terletak di tengah kota yang memiliki pengaruh besar terhadap kegiatan ekonomi. Pasar modern yang mengalami pertumbuhan cukup pesat saat ini adalah Minimarket. Minimarket menerapkan sistem swalayan, dimana pembeli mengambil sendiri barang yang ia butuhkan dari rak- rak dagangan dan membayar nya dikasir. Minimarket dengan konsep waralaba yang terdapat diberbagi wilayah Indonesia termasuk Sulawesi selatan adalah Alfamart, Alfamidi, dan Indomart. Minimarket banyak dibangun sekitar pemukiman Masyarakat, dengan tujuan agar masyarakat yang ingin berbelanja tidak mengalami lagi kesusahan untuk mencari transportasi ke pasar. Di Minimarket ini banyak telah disediakan berbagai macam kebutuhan pokok sehari-hari dan distribusi barang berasal dari distributor atau importir yang langsung dipasok ke gudang pusat atau ke toko. Minimarket sangat menjaga kenyamanan konsumen mulai dari kualitas barang yang dijual, tanggal expayer suatu barang, serta susunan barang yang dijual dan tingkat pelayanan yang efektif. Sehingga masyarakat umum tidak lagi kesusahan untuk ke pasar karena di Minimarket sudah menyiapkan segala kebutuhan pokok konsumen. Dengan banyaknya kenyamanan-kenyamanan dan fasilitasfasilitas yang diberikan pihak Minimarket, maka Minimarket memposisikan diri menjadi tempat perbelanjaan yang diminati masyarakat. Munculnya Minimarket juga dapat mengurangi pengangguran dengan membuka banyak kesempatan kerja, oleh karena itu proyek Minimarket memberikan prospek yang lebih baik pada masa sekarang maupun yang akan datang.Tumbuh pesatnya Minimarket ke wilayah pemukiman berdampak positif bagi konsumen karena harga yang ditawarkan lebih murah dan berperan dalam penyerapan tenaga kerja, namun berdampak buruk bagi pedagang di pasar tradisional yang telah lama berada di wilayah tersebut. Keberadaan Minimarket yang memberikan berbagai daya tarik membuat para konsumen beralih ke Minimarket tersebut dengan kualitas pelayanan lebih baik dari 


\section{PAY Jurnal Keuangan dan Perbankan. Vol. 2 No. 1, Juni 2020}

pedagang tradisional. Hal ini tentu saja membuat harapan pedagang untuk mencari penghasilan guna memenuhi kebutuhan sehari-hari dari keuntungan yang diperoleh mulai sedikit tersendat. Seperti yang terjadi pada Kabupaten Maros khususnya di Kecamatan Turikale. Kabupaten Maros adalah salah satu daerah Tingkat II di provinsi Sulawesi Selatan, Indonesia. Ibu kota kabupaten ini terletak di Kota Maros. Kabupaten ini memiliki luas wilayah $1.619,12 \mathrm{~km}^{2}$, Kabupaten Maros terdiri dari 12 Kecamatan. Disini banyak dibangun pasar modern (Minimarket) pada setiap sistem jaringan jalan yang dianggap potensial oleh para pebisnis, dilihat setiap sisi jalan selalu didapati bangunan Minimarket yang semakin meningkat. Hal ini disebabkan karena kemajuan ilmu pengetahuan dan teknologi sehingga pebisnis membuka Minimarket dalam bentuk pasar modern. Berdasarkan sumber data yaitu Dinas Koperasi,UMKM, dan Perdagangan (KOPUNDAG) terdapat 47 unit Minimarket yang tersebar di Kabupaten Maros. Tentu hal ini memberikan pengaruh terhadap pendapatan pedagang, khususnya di Kecamatan Turikale yang paling banyak didirkan Minimarket yaitu sebanyak 17 unit. Persebaran Minimarket ini membawa dampak buruk bagi pendapatan pedagang, karena Minimarket yang sudah memonopoli pasar sehingga dapat mengurangi pendapatan pedagang di pasar tradisional. Hal ini membuat pedagang di pasar terpuruk. Berdasarkan uraian latar belakang di atas maka penulis tertarik untuk meneliti yang berjudul "Pengaruh Keberadaan Minimarket terhadap Tingkat Pendapatan Pedagang Pasar Tradisional di Kecamatan Turikale Kabupaten Maros".

\section{B. Rumusan Masalah}

Berdasarkan latar belakang di atas, peneliti merumuskan permasalahan untuk memfokuskan masalah yang diteliti dan dianalisis dalam bentuk pertanyaan penelitian yaitu Bagaimana pengaruh keberadaan Minimarket terhadap tingkat pendapatan pedagang Pasar Tradisional di Kecamatan Turikale Kabupaten Maros?

\section{Tujuan Penelitian}

Adapun tujuan dari penelitian ini adalah untuk mengetahui pengaruh keberadaan Minimarket terhadap Tingkat Pendapatan Pedagang Pasar Tradisional di Kecamatan Turikale Kabupaten Maros.

\section{TINJAUAN PUSTAKA}

\section{A. Pendapatan}

1. Pengertian Pendapatan

Menurut Nazir

(2010:17)

Pendapatan merupakan suatu hasil yang diterima oleh seseorang atau rumah tangga dari berusaha atau bekerja. Nugraha (2018:8) Secara garis besar pendapatan didefinisikan sebagai jumlah harta kekayaan awal periode ditambah perubahan penilaian yang bukan diakibatkan perubahan modal dan hutang.

\section{Jenis-Jenis Pendapatan}

Suparmoko (2010:15) Secara garis besar pendapatan digolongkan menjadi 3 (tiga) golongan yaitu :

a. Gaji dan Upah. Imbalan yang diperoleh setelah orang tersebut melakukan pekerjaan untuk orang lain yang diberikan dalam waktu satu hari, satu minggu, dan satu bulan.

b. Pendapatan dari Usaha Sendiri. Merupakan nilai total dari hasil produksi yang dikurangi dengan biaya-biaya yang dibayar dan usaha ini merupakan usaha milik sendiri atau keluarga dan tenaga kerja 


\section{PAY Jurnal Keuangan dan Perbankan. Vol. 2 No. 1, Juni 2020}

berasal dari anggota keluarga sendiri, nilai sewa kapital milik sendiri dan semua biaya ini biasanya tidak diperhitungkan.

c. Pendapatan dari Usaha Lain. Pendapatan yang diperoleh tanpa mencurahkan tenaga kerja, dan ini biasanya merupakan pendapatan sampingan antara lain, pendapatan dari hasil menyewakan asset yang dimiliki seperti rumah, ternak dan barang lain, bunga dari uang, sumbangan dari pihak lain, pendapatan dari pensiun, dan lainlain.

\section{B. Pasar}

\section{Pengertian Pasar}

Hanafie (2010:176) pasar memiliki arti yang lebih luas dari pada hanya sekedar tempat pertemuan antara penjual dan pembeli untuk mengadakan transaksi jual beli barang. Pengertian pasar tidak harus dikaitkan dengan suatu tempat yang dinamakan pasar dalam pengertian sehari-hari.

\section{Fungsi Pasar}

Wijayanti (2011:20) ada 5 (lima) fungsi pasar yaitu :

a. Mempertahankan dan mempersiapkan kebutuhan di masa depan

b. Penyelenggara penjatahan (rationing);

c. Pengorganisir produksi;

d. Pendistribusi barang;

e. Menetapkan nilai (sets value)

\section{METODE ANALISIS}

\section{Regresi Linear Sederhana}

Regresi linear sederhana digunakan untuk mengukur pengaruh variabel bebas terhadap variabel terikat. Adapun rumus dari regresi linear sederhana (Juliansyah Noor, 2014 :64) yaitu :

$\mathrm{Y}=\mathrm{a}+\mathrm{bx}$

Keterangan :
$\mathrm{X}=$ Rasio aktivitas

$\mathrm{Y}=$ Pertumbuhan laba

$\mathrm{a}=$ Konstanta

b = Koefisien Regresi

\section{Korelasi}

Korelasi merupakan salah satu teknik analisis dalam statistik yang digunakan untuk mencari hubungan antara dua variabel yang bersifat kuantitatif (Juliansyah Noor, 2014 :49) adapun rumus korelasi yaitu :

$\mathrm{r}=\mathrm{n} \Sigma \mathrm{xy}-(\Sigma \mathrm{x}) \cdot(\Sigma \mathrm{y})$

$\sqrt{\left\{(\mathrm{n} \Sigma \mathrm{x})^{2}-\left(\sum \mathrm{x}\right)^{2}\right\}} \sqrt{\left\{\left(\mathrm{n} \sum \mathrm{y}\right)^{2}-\left(\sum \mathrm{y}\right)^{2}\right\}}$

Keterangan :

$\mathrm{N}$ = Banyaknya Pasangan data $\mathrm{X}$

dan

$\Sigma \mathrm{X}=$ Total Jumlah dari Variabel $\mathrm{X}$

$\Sigma \mathrm{y} \quad=$ Total Jumlah dari Variabel Y

$\Sigma \mathrm{x}^{2} \quad=$ Kuadrat dari Total Jumlah

Variabel X

$\Sigma \mathrm{y}^{2}=$ Kuadrat dari Total Jumlah Variabel Y

$\mathrm{r}=$ kuofisien korelasi persen

$\Sigma x y=$ Hasil Perkalian dari Total Jumlah Variabel X dan Variabel Y

Tabel Interprestasi koofisien korelasi Nilai $r$

\begin{tabular}{|c|c|}
\hline $\begin{array}{c}\text { Interval } \\
\text { koefisien }\end{array}$ & $\begin{array}{c}\text { Tingkat } \\
\text { hubungan }\end{array}$ \\
\hline $0,00-0,199$ & Sangat rendah \\
$0,20-0,399$ & Rendah \\
$0,40-0,599$ & Sedang \\
$0,60-0,799$ & Kuat \\
$0,80-1,000$ & Sangat kuat \\
\hline
\end{tabular}

Sumber :sugiono(2014:250)

\section{Koefisien Determinasi}

Koefisien determinasi yaitu untuk mengetahui seberapa besar pengaruh variabel bebas terhadap variabel terikat atau dapat dkatakan seberapa besar pengaruh variabel $\mathrm{X}$ terhadap variabel $\mathrm{Y}$ (Juliansyah Noor, $2014: 50$ )

$$
K d=r^{2} \times 100 \%
$$

Keterangan : $\mathrm{Kd}=$ Nilai Koefisien Determinasi 
PAY Jurnal Keuangan dan Perbankan. Vol. 2 No. 1, Juni 2020

$r^{2}=$ Nilai Kuadrat Koefisien

Determinasi

\section{Uji t}

Uji t dilakukan untuk menentukan nilai koefisien regresi terhadap variabel dependen apakah signifikan atau tidak. Uji $\mathrm{t}$ dapat dihitung dengan rumus: (Juliansyah Noor, 2014 :70)

Uji $\mathrm{T}=\mathrm{t}=r=\frac{\sqrt{\mathrm{n}-2}}{\sqrt{1-r^{2}}}$

Keterangan :

$\mathrm{t}=$ Nilai Uji $\mathrm{t}$

$r=$ Koefisien Korelasi

$\mathrm{n}=$ Jumlah Data

$r^{2}=$ Koefisien Determinasi

\section{HASIL PENELITIAN}

Jumlah Minimarket di Kecamatan Turikale Kabupaten Maros

\begin{tabular}{|c|c|c|}
\hline Tahun & $\begin{array}{c}\text { Jumlah } \\
\text { Minimarket } \\
\text { (Unit) }\end{array}$ & $\begin{array}{c}\text { Pertumbuhan } \\
(\%)\end{array}$ \\
\hline 2011 & 18 & 18 \\
\hline 2012 & 35 & 35 \\
\hline 2013 & 23 & 23 \\
\hline 2014 & 6 & 6 \\
\hline 2015 & 0 & 0 \\
\hline 2016 & 0 & 0 \\
\hline 2017 & 0 & 0 \\
\hline 2018 & 18 & 18 \\
\hline
\end{tabular}

Sumber data : Dinas Penanaman Modal dan Pelayanan Terpadu Satu Pintu Kabupaten Maros 2019

Dalam penelitian ini keberadaan Minimarket diukur dari pertumbuhannya dapat dilihat dari tabel tersebut menunjukkan bahwa jumlah Minimarket setiap tahun makin bertambah dimana saat ini jumlahnya yang tersebar di Kecamatan Turikale sebanyak 17 unit. Sekalipun hanya 17 unit tetapi berdasarkan hasil wawancara dengan responden semua mengatakan bahwa keberadaan Minimarket sangat mempengaruhi tingkat pendapatan mereka.
1. Analisis Regresi Linear Sederhana

a. Nilai konstan dari unstandardized coefficients dalam kasus ini nilainya sebesar 59,620. Angka ini merupakan angka konstan dan dalam rumus disimbolkan (a) yang berarti bahwa sekalipun terjadi perubahan pertumbuhan Minimarket dan penurunan tingkat pendapatan pedagang pasar tradisional di Kecamatan Turikale Kabupaten Maros nilai konstannya (a) tidak mengalami perubahan.

b. Nilai koefisien Regresi (b) sebesar 0,630 yang berarti bahwa setiap penambahan Minimarket (X) sebesar 1 unit, maka akan mempengaruhi penurunan tingkat pendapatan pedagang pasar tradisional di Kecamatan Turikale akan mengalami penurunan sebesar -0,630 atau dengan kata lain, jika Minimarket bertambah sebanyak 1 unit akan menurunkan pendapatan pedagang sebesar $-0,630$, sehingga

persamaan dapat ditulis sebagai berikut : $\mathrm{Y}=\mathbf{5 9 , 2 1 8}-\mathbf{0 , 6 3 0 X}$

Tingkat signifikasi pengaruh variabel $(\mathrm{x})$ Minimarket terhadap variabel (y) tingkat pendapatan jika thitung < nilai sig berarti kedua variabel memiliki pengaruh signifikan dimana nilai thitung $-1,551$ dan nilai sig 0,172 jadi dapat ditulis $1,551<0,172$ yang berarti bahwa Keberadaan Minimarket berpengaruh negatif dan signifikan terhadap tingkat pendapatan Pedagang Pasar Tradisional di Kecamatan Turikale Kabupaten Maros. 


\section{PAY Jurnal Keuangan dan Perbankan. Vol. 2 No. 1, Juni 2020}

Nilai koefisien korelasi (r) menunjukkan sebesar $-0,535$ yang berarti hubungan kedua variabel (x) Minimarket ke variabel (y) tingkat Pendapatan Pedagang Pasar Tradisional adalah negatif dan untuk melihat kriteria penilaian koefisien korelasi yang dimana nilai korelasi berada pada 0,40 - 0,599 berarti kedua variabel menunjukan hubungan yang sedang.

\section{Analisis Koefisien Determinasi}

Nilai $R$ Square sebesar 0,286 nilai ini mengandung arti bahwa besarnya pengaruh keberadaan Minimarket (X) terhadap Tingkat Perubahan Pendapatan Pedagang di Pasar Tradisional (Y) sebesar 28,6 \% sedangkan 71,4\% Tingkat Pendapatan Pedagang dipengaruhi oleh variabel lain yang tidak diteliti pada penelitian ini diantaranya menurut Suparmoko (2018:25) adalah modal, lama usaha, dan tenaga kerja.

\section{Uji T}

thitung $-1,551$ sedangkan untuk ttabel dapat diukur $\mathrm{df}=\mathrm{n}-\mathrm{k}$ jadi $\mathrm{df}=8$ $-2=6$, dengan nilai yang didapat pada tabel sebesar 2,44691 jadi nilai thitung = $-1,551$ dan ttabel $=2,44691$, artinya $1,551<2,44691$, ini menandakan bahwa hipotesis "ditolak" artinya hipotesis tidak sesuai dengan hasil penelitian di mana hipotesisnya menyatakan keberadaan Minimarket berpengaruh terhadap tingkat Pendapatan Pedagang Pasar Tradisional di Kecamatan Turikale Kabupaten Maros sedangkan setelah dianalisis mengunakan Regresi Linear Sederhana yang hasil nya Keberadaan Minimarket berpengaruh negatif dan Signifikan Terhadap Tingkat Pendapatan Pedagang Pasar Tradisional di Kecamatan Turikale Kabupaten Maros.

\section{KESIMPULAN DAN SARAN}

Berdasarkan analisis yang dilakukan terhadap pengaruh rasio aktivitas terhadap pertumbuhan laba bersih pada PT. Japfa Comfeed Indonesia TBK.dengan metode regresi sederhana berganda maka di ambil kesimpulan adalah sebagai berikut:

1. Jumlah Minimarket yang semakin bertambah tiap tahun seiring dengan penurunan tingkat pendapatan pedagang yang semakin drastis sebesar $75 \%$ hingga $33 \%$.

2. Nilai konstan dari unstandardized coefficients dalam kasus ini nilainya sebesar 59,620 dan Nilai koefisien Regresi (b) sebesar -0,630 sehingga persamaannya dapat ditulis $\mathbf{Y}=\mathbf{5 9 , 2 1 8}$ - 0,630X. Sedangkan Keberadaan Minimarket berpengaruh negatif dan signifikan terhadap tingkat Pendapatan Pedagang Pasar Tradisional di Kecamatan Turikale Kabupaten Maros karena thitung lebih kecil dari nilai sig yaitu sebesar $-1,551<0,172$.

3. Nilai koefisien korelasi (r) Menunjukkan sebesar -0,535 dimana nilai korelasi berada pada 0,40 0,599 berarti kedua variabel menunjukan hubungan yang sedang.

4. Pengaruh keberadaan Minimarket (X) terhadap tingkat perubahan Pendapatan Pedagang di Pasar Tradisional (Y)sebesar 28,6\%.

5. Nilai thitung $-1,551$ sedangkan untuk ttabel 2,44691, artinya $-1,551<2,44691$, ini menandakan bahwa hipotesis "ditolak" karena thitung lebih kecil daripada ttabel.

Berdasarkan hasil penelitian dan pembahasan masalah selanjutnya penulis akan mengemukakan saran-saran yang mungkin bermanfaat bagi pembaca dan 


\section{PAY Jurnal Keuangan dan Perbankan. Vol. 2 No. 1, Juni 2020}

perusahaan, untuk saat ini dan dimasa yang akan datang adalah sebagai berikut:

1. Diharapkan untuk pedagang agar lebih meningkatkan jumlah dan variasi barang yang dijual, dari penambahan berbagai jenis barang jualan konsumen akan tertarik berbelanja karena dapat menyediakan segala kebutuhan yang diinginkan konsumen.

2. Diharapkan pengelola pasar lebih memperhatikan kondisi pasar tradisional kecamatan turikale agar dapat bersaing dengan Minimarket seperti menjaga kebersihan pasar tradisional agar konsumen dapat merasa nyaman berbelanja di pasar tradisional.

\section{DAFTAR PUSTAKA}

A.P, Hardian Yossi. 2018.Pengaruh Minimarket Terhadap Pendapatan Pedagang Pasar Tradisional. Purwekerto:Skripsi.

Daulay, Yolanda Sari. 2018. Pengaruh Keberadaan Minimarket terhadapap Warung Tradisional Kecamatan Rantau Utara Kabupaten Labuhanbatu Provinsi Sumatera Utara.Sumatera:jurnal.

Dewi, Triadi Ayu Ni Komang. 2013. Dampak Minimarket terhadap Eksistensi Warung Tradisional Di Kota Singaraja.SingarajaBali:Universitas Pendidikan Ganesha.

Hanafie, Rita. 2010. Dalam Kamus Ekonomi \&Bisnis. Jakarta: PT. Gramedia Pustaka Utama.
Harahap. 2009. Teori Kritis Laporan Keuangan. Jakarta: Bumi Aksara.

Harmono. 2011. Manajemen Keuangan. Jakarta: Bumi Aksara.

Hery. 2012. Analisis Laporan Keuangan. Jakarta: Bumi Aksara.

Irwan, Mahfuzi, 2016. Revitalisasi Pasar Tradisional di Tengah Arus Pasar

Modern. Yogyakarta:Universitas Negeri Yogyakarta.

Kasmir. 2013. Analisa Laporan Keuangan. Jakarta: PT. Raja Grafindo.

Kusnadi. 2009. Akuntansi Keuangan Menengah. Malang:Universitas Brawijaya.Malang.

Kotler,Philip. 2010. Manajemen pemasaran.Jakarta:Pt. Indeks. Jilid I Dan II.

Malano, Hermanto. 2011. Selamatkan Pasar Tradisional. Jakarta: Gramedia.

Munandar, M. 2010. Pokok-pokok Intermediate Accounting. Yogyakarta:

Gajah Mada.

Munawir,S.2010.Analisis Laporan Keuangan Akuntansi.Jakarta : Salemba Empat.

Muslichah. 2018. Akuntansi Usaha Kecil Menengah. Jakarta: Indomedia Pustaka. 
PAY Jurnal Keuangan dan Perbankan. Vol. 2 No. 1, Juni 2020

Nashiruddin, Much. 2017. Pengaruh Perkembangan Alfamart terhadap Pendapatan Pedagang Kecil. Surkarta:Jurnal.

Nazir. 2010. Analisis Determinan Pendapatan Pedagang Kaki Utara.

Noor, Juliansya. 2014. Analisis Data dan Penelitian Ekonomi dan Manajemen. Jakarta: PT. Gramedia Widiasarana Indonesia.

Nugraha, S. 2018. Analisis Faktor yang Berpengaruh terhadap Tingkat Pendapatan Tenaga Kerja Pada Industri Kecil Manik Desa Plumbon Gambang Kecamatan Gudo Kabupaten Jombang (Doctoral Dissertation, University of Muhammadiyah Malang).

Perpres. 112. 2007. Tentang Pembangunan. Penataan dan Pembinaan Pasar Tradisional.

Pramono, Hery Ananta. 2011. Menahan Serbuan Pasar Modern. Yogyakarta: Lembaga Ombudsman Swasta Diy.

Simamora, Bilson. 2011. Memenangkan Pasar dengan Pemasaran Efektif dan Profitabel. Jakarta: PT. Gramedia Pustaka Utama.

Sinaga, Pariaman. 2008. Pasar Modern VS Pasar Tradisional. Jakarta: Kementerian Koperasi dan UKM.

Siswanto, 2013. Pengantar Manajemen. 17 Jakarta: PT. Bumi Aksara.
Subramaya. 2010. Analisa Laporan Keuangan. Jakarta: Salemba Empat.

Sugiyono. 2017. Metode Penelitian dan Pengembangan. Bandung: Alfabeta.

Sukirno. 2008. Teori Pengantar Ekonomi Pengantar. Yogyakarta: Pustaka Widyatama. Edisi Ketiga.

Suparmoko, M. 2010. Pengantar Ekonomi Makro. Jakarta: BPFE. (Hlm 15 dan 25).

Tohar, M., 2012. Membuka Usaha Kecil. Yogyakarta: Kanisius.

Wijayanti. 2011. Analisis Pengaruh Perubahan Keuntungan Usaha Warung Tradisional Dengan Munculnya Minimarket (Studi Kasus di Kecamatan Pedurungan Kota Semarang).

Yudohusodo, $\quad$ Siswono. 2012. Transmigrasi Kebutuhan Negara Kepulauan Berpenduduk Heterogen dengan Persebaran yang Timpang. Jakarta: PT Jurnalindo Aksara Grafika. 